\title{
Treatment of Knee Osteochondral Defects with
}

\section{Mosaicoplasty Technique}

\author{
Mohsen Fawzy Omar, MD ${ }^{1}$, Mohammed a Gheith, MD \\ ${ }^{1}$ Lecturer of Orthopedic Surgery, Zagazig University, Egypt \\ ${ }^{2}$ Assistant professor, Orthopedic Surgery, Zagazig University, Egypt \\ ${ }^{1}$ yousufmmkh@gmail.com \\ 2ymkhairy@medicine.zu.edu.eg
}

Received Date: May 20, 2017

Accepted Date: June 01, 2017

Published Date: June 20, 2017

Abstract

Background: Due to the avascular nature of the articular cartilage and the limited stem cell population the lesions of articular cartilage have limited ability to repair. Another factor is the constant and repeated loads on the articular cartilage of the knee that create unsound mechanical environment for healing.

Objective: To evaluate the results of osteochondral autograft technique in treatment of chondral and osteochondral defects.

Material and Methods: From May 2013 to November 2016 sixteen patients with chondral or osteochondral defects of one of the femoral condyles were treated using the osteochondral grafts technique. Open technique was used in (10 patients) and arthroscopic technique in (6 cases). For patient evaluation we used two scores: the chondral defect scoring system, and Lysholm score.

Results: according to the Chondral defect scoring system, significant improvement of the subjective score of the pain, swelling, locking and full weight bearing. The mean total (CGSS - objective \& subjective) was improved from 47.6 ( $S D \pm 15.3$ ) preoperatively to a postoperative mean of $83(S D \pm 11.2)$. The Lysholm score shown significant improvement for the Limp, locking sensation, using cane, giving way, swelling, climbing stairs and also for squatting.

Conclusion: Mosaicoplasty as one-step procedure, has low morbidity, independent of laboratory use. Based upon the results of this study, osteochondral autograft is a good solution for treatment of full thickness cartilage damage.

Keywords: Mosaicplasty, Autograft, Osteochondral defect, Knee.

This prospective study was conducted on sixteen patients in Zagazig University in Sharqia between 2013 and 2016.

\section{INTRODUCTION}

The articular cartilage is an avascular, hypo cellular, lymphatic tissue. Thelow-friction, highly durable and wear-resistant surface of articular cartilage is due to the dense collagen and proteoglycan matrix. The function of the smooth articular surface is to give pain-free gliding surface and shock absorption of the joints during skeletal motion. Degeneration of this articular cartilage surface can lead to joint arthritis due to its minimal reparative potential [1]. The mechanism of injury in patients with chondral or osteochondral injuries is typically an axial loadingcombined with either twisting, or shearing-type injury or it may be an impaction injury due to significant blunt trauma. The clinical presentations of the patients usually are pain increasing with weight 
bearing, recurrent effusion,locking and catching [2].Imaging of the knee includes plain x-ray weight-bearing (AP) anteroposterior view in full extension for both knees, lateral view, and an axial patellofemoral joint view. Magnetic resonance imaging (MRI) is helpful in detecting the extent of articular cartilage lesions [3]. The main goals of surgical treatment of symptomatic chondral defects are relieving symptoms, improvement of joint congruence, and prevention of further deterioration.The technique of Osteochondral autograft transfer (OAT) involves the transfer of plugs of healthy cartilage combined with its subchondral bone from decreased load bearing areato the full-thickness lesion in another important weight bearing area of the knee. This procedure can be done arthroscopically or open through an arthrotomy as a single-stage procedure. The most important disadvantages of this technique are the donor-site morbidity and the shortage of the available graft for harvesting [4].

\section{Patients and Methods}

Through the period from May 2013 to November 2016 sixteen patients with chondral or osteochondral defects of one of the femoral condyles were treated using the osteochondral grafts technique. Open technique was used in (10 patients) and arthroscopic technique in ( 6 cases). The patients with severe osteoarthritic or sever lower limb deformity were excluded from the study. Autologous osteochondral grafts from the same knee were used in all patients. The mean age of the patients was 26.1 years $(S D \pm 7.6)$ ranged from 18 and 37 years, with the body weight ranged from $65-98 \mathrm{Kg}$ (mean of $77.6 \mathrm{Kg}-\mathrm{SD} \pm 10.2$ ) and the height of the patients ranged from 164 to $190 \mathrm{~cm}$ with a mean of $172.4 \mathrm{~cm}$ ( SD \pm 9.8 ). There were 12 males $(75 \%)$ and 4 females $(25 \%)$. The right knee was injured in12 patients $(75 \%)$ and the left knee in 4 patients $(25 \%)$. Ten patients have the defects in the dominant knee $(62.5 \%)$ and 6 patients in the non- dominant knee (37.5\%). The defect was in the medial femoral condyle (M.F.C.) in 14 patients (87.5\%) and in the lateral femoral condyle (L.F.C.) in 2 patients (12.5\%). The man complaint was knee pain in all of the cases, while catching was found in 8 patients (50\%), effusion in 10 patients (62.5\%).The plain radiography of AP and lateral standing views, and axial patellofemoral view added to M.R.I. were used in all cases (Fig. 1). For patient evaluation we used two scores: the chondral defect scoring system(Table 1) [5], andLysholm score(Table 2) [6].

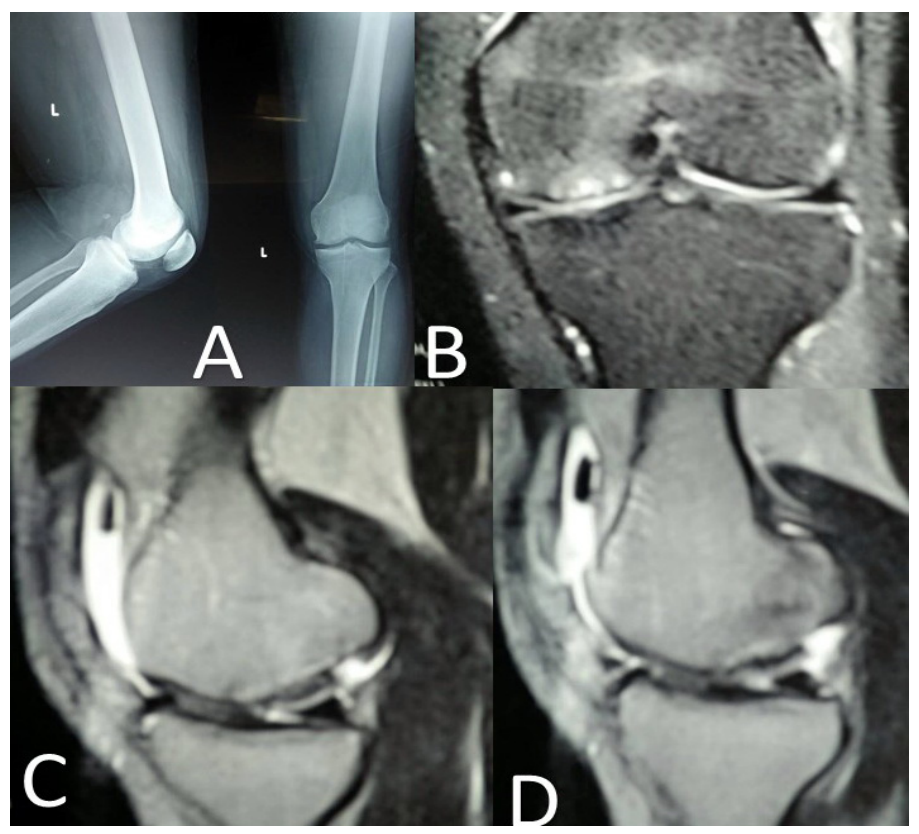

Figure1. A) plain x-ray preoperative; B.C.D) (coronal - sagital view. MRI showing osteochondral defect on M.F.C 
Table1. Chondral defecting scoring sistem

\begin{tabular}{|c|c|c|c|c|c|c|c|c|c|}
\hline & & & Rig & t Knee & & & & th Knee & \\
\hline & th & NQNE & MILD & MODERATE & SEVERE & NONE & MILD & MODERATE & SEVERE \\
\hline & Pain & 01 & 02 & 3 & 04 & 01 & 02 & 03 & 04 \\
\hline & Swelling & 01 & 2 & 03 & 04 & 01 & 02 & 03 & 04 \\
\hline & Partial Giving Way & 01 & 02 & 03 & 04 & 01 & 02 & 03 & 04 \\
\hline & Full Giving Way & 01 & 02 & 03 & 04 & 01 & 02 & 03 & 04 \\
\hline & Locking & 01 & 02 & 03 & 04 & 01 & 02 & 03 & 04 \\
\hline & $\begin{array}{l}\text { Noise Sensations } \\
\text { (popping. grinding, oracting) }\end{array}$ & 01 & 02 & 03 & 04 & 01 & 02 & 03 & 04 \\
\hline & Joint Stiffness & 01 & 02 & 03 & 04 & 01 & 02 & 03 & 04 \\
\hline
\end{tabular}

2. Please indicate whether you walk with a limp. ONone OMild OModerate OSevere

3. At your highest level of activity, do you experience any difficulties while performing the following tasks:
1) Walking
2) Squatting
0102
03
04
3) Ascending Stairs
$01 \quad 02$
03
04
4) Descending Stairs
01
$\circ 2$
03
04
5) Running
01
02
03
04
01
02
03
04

NONE MILD

MODERATE SEVERE

Rate the following on a scale from 10 to 1 . BEsT WORST

4. Your current activity level in Sports.

$\begin{array}{lllllllllll}010 & 09 & 08 & 07 & 06 & 0 & 5 & 04 & C_{3} & O_{2} & 01\end{array}$

5. Rate your current activity level in Activities of Daily Living.

$\begin{array}{llllllllll}010 & 09 & 08 & 07 & 06 & 05 & 04 & 03 & 02 & 01\end{array}$

6. Rate your current ability to do Strenuous Work (vigorous activities).

$\begin{array}{llllllllll}010 & 09 & 08 & 07 & 06 & 05 & 04 & 03 & 02 & 01\end{array}$

7. Rate your current ability to do Sedentary Work (sitting activities)

Rate the following on a scale from 10 to 1.

$\begin{array}{lll}\text { Very } & \text { Very } \\ \text { Satisfied } & \text { Neutral } & \text { Unsatisfied }\end{array}$

How satisfied are you with your current OUTCOME?

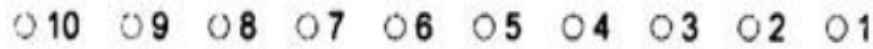


Table2. Lysholm score

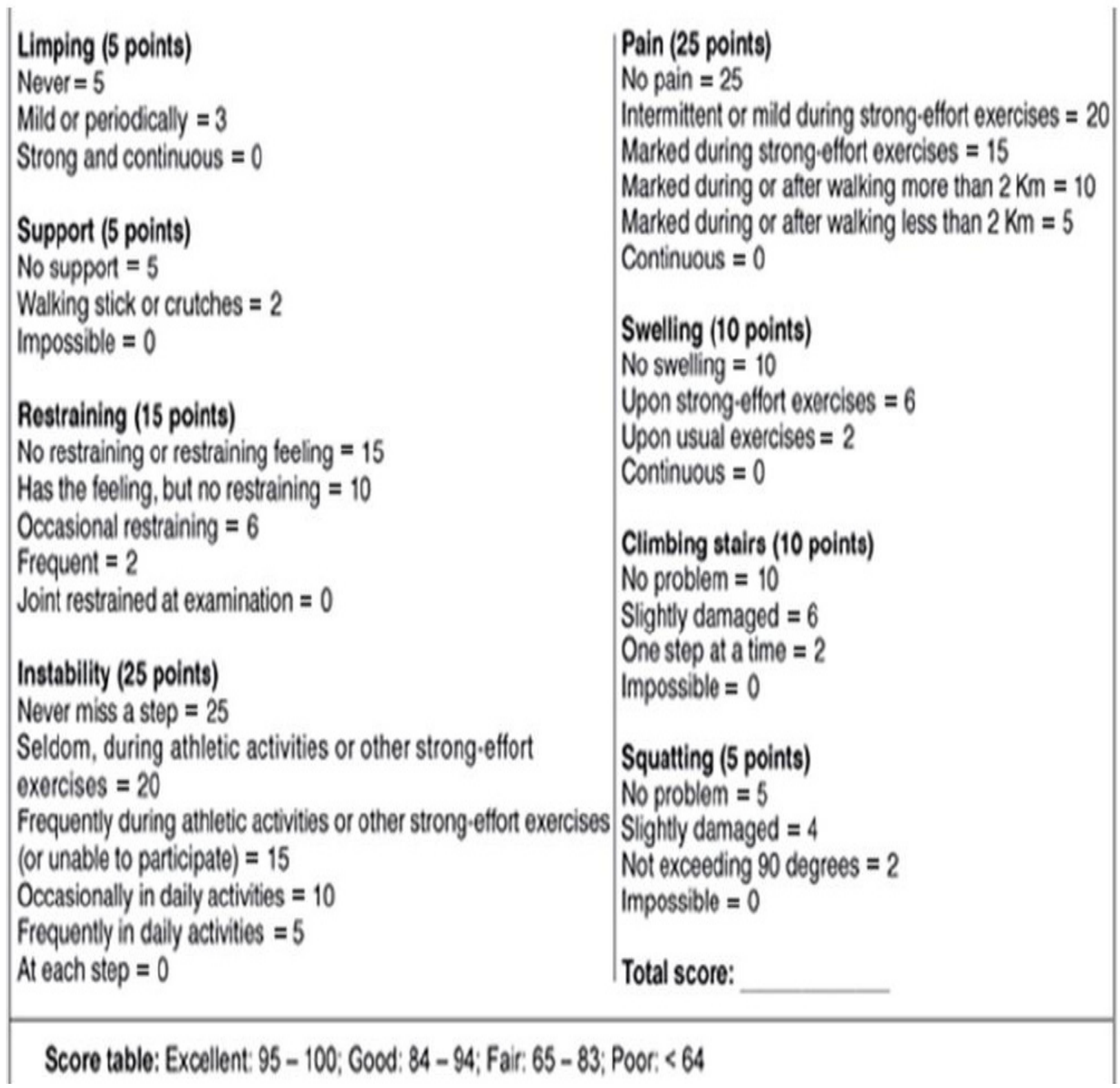

\section{Operative Technique Fig 2}

The system used in this work was the OATS (Osteochondral Autograft Transfer system of Arthrex). Under spinal anesthesia and pneumatic tourniquet, diagnostic arthroscopy was done first for all cases. Third generation cephalosporin was administrated intravenously before tourniquet application. The average time of operation ranged from 80 to 100 minutes. Through the arthroscopic probing, the grade of the defect, cartilage condition, subchondral osseous involvement, the depth and roughly the size of the lesion were determined. Calculating the expected number of grafts was made using a measuring tamp thatintroduced through the arthroscopic portal. Finally, the accessibility of the defect wasassessedeither arthroscopically or opens technique can be used [7]. 


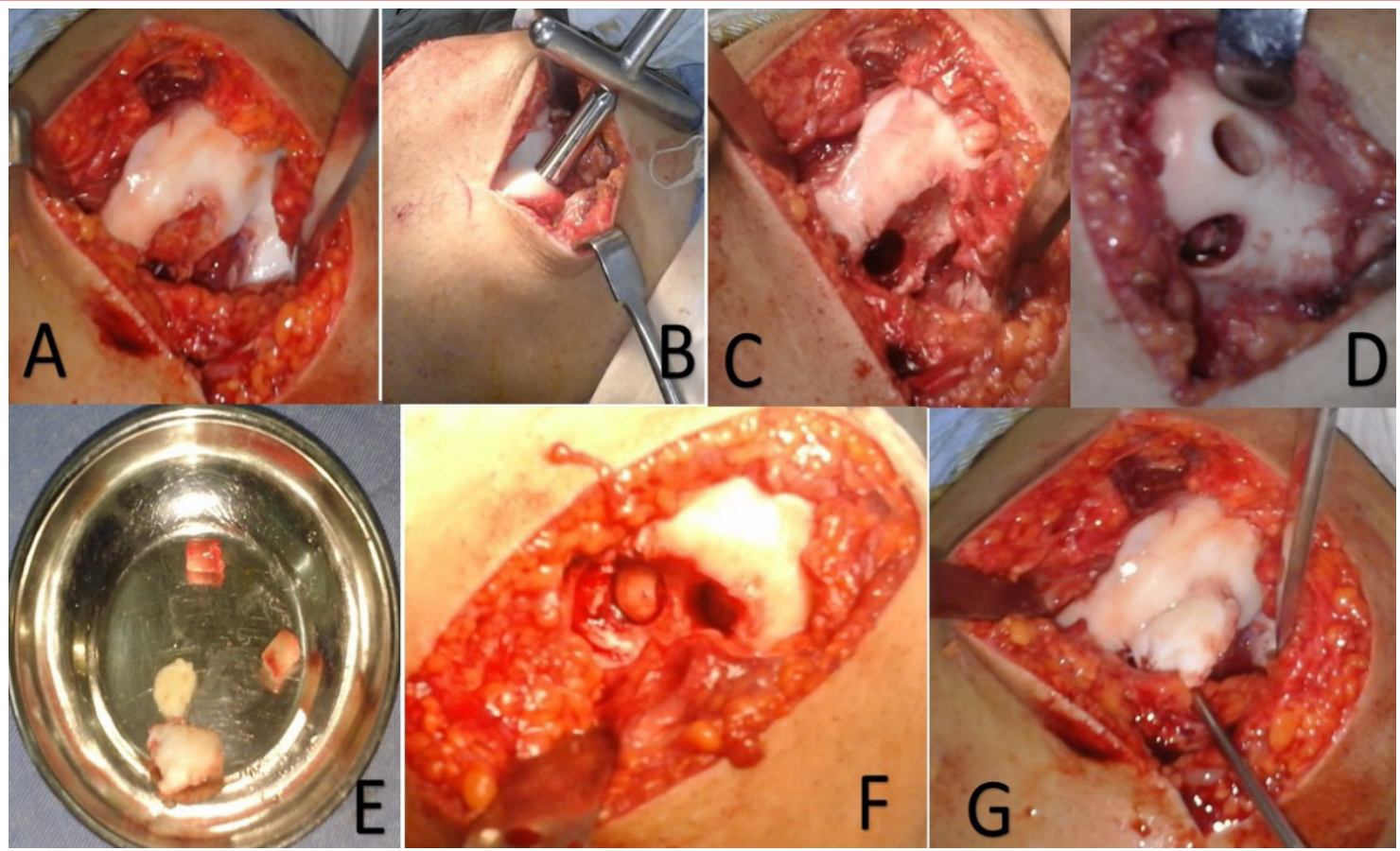

Figure2. surgical technique of mosaicoplasty

\section{SuRgical GRAFTing TECHNIQUE}

Arthroscopic procedure (used in 6 patients): using the recipient harvesting tube introduced through the access portal to provide a perpendicular access to the defect with hammering on $\mathrm{T}$ handle under observation.The depth of introduced tube in the articular surface was determined by the caliber over the tube to approximately reach the length of $13 \mathrm{~mm}$. The following step was the rotation of the Thandle $90^{\circ}$ clock wise and anti-clockwise for three to four times followed by rocking movement at right angles.Then releasing the harvesting tube from the $\mathrm{T}$ handle pulling the core out and applying graft harvesting tube. The graft was taken from Intercondylar notch at sites of notchplasty in 4 cases, and from the (L. F. C.) above the level of the sulcus terminalis in two cases. A needle was introduced to clarify the incision from outside which was at the upper lateral border of lateral femoral condyle. The tube was then delivered perpendicular to the articular cartilage under vision through a small skin incision under the arthroscope to $15 \mathrm{~mm}$ depth. The tube was then rotated $90^{\circ}$ clock wise and anticlock wise with rocking in the two directions, then rotated gently and extracted. The graft tube was placed at the prepared tunnel, and the graft was hammered in a perpendicular direction. The hammering of the graft was continued until the cartilage was flushed with condylar surface [8].

Open Technique (used in 10 cases): when the defect was not accessible for arthroscopic technique we usedanterior midline skin incision of the knee opening the subcutaneous tissue, approaching the knee through the medial parapatellar plane exposing the both condyles and the patellar undersurface. The technical procedure was completed asin arthroscopic technique for grafting. Over suction drain, the wound was closed in layers and crepe bandage was applied [7].

Post-operatively, the weight bearing was restricted 4 to 6 weeks, with early (R $0 \mathrm{M}$ ) and isometric quadriceps strengthening. Partial weight bearing using one crutch for two weeks followed by full range of motion was allowed after 2 months. For two to four weeks full R.O.M and full weight bearing were promoted [9].

Postoperative complications reported in this work as hemarthrosis and effusion in two cases (12.5\%), postoperative stiffness in two cases with open procedure (12.5\%), and donor site pain in 4 cases (25 \%). 


\section{RESULTS}

\section{The intraoperative findings}

Mild to moderate synovitis was found in 8 patients (50 \%) and arthroscopic shaving was done, while 8 patients (50\%) did not need shaving.

Meniscal injury was found in 6 patients (4 medial meniscus and 2 lateral meniscus) and arthroscopic meniscectomy for all 6 patients $(37.5 \%)$ were done at the same sitting, while other 10 patients had no injury in the menisci (62.5\%).

Loose bodies were found in 4 patients as chondral and osteochondral parts in the knee which form (25\%) and 12 patients have no loose body(75\%).

The mean size of the cartilage defects was $2.1 \mathrm{~cm}(\mathrm{SD} \pm 0.8$ ) ranged from $1.5 \mathrm{~cm}$ to $3 \mathrm{~cm}$ in the diameter with the number of grafts between 1-4 grafts per defect with a mean 2.5grafts (SD \pm 1.1 ), and according to grading of lesion from grade 1-4 with mean 2.9 (SD \pm 1.1 ).

\section{Clinical Results}

The mean total (CGSS - objective \& subjective) was improved from 47.6 (SD \pm 15.3 ) preoperatively to a postoperative mean of $83(\mathrm{SD} \pm 11.2)$ (Chart 1$)$.

Chart1.

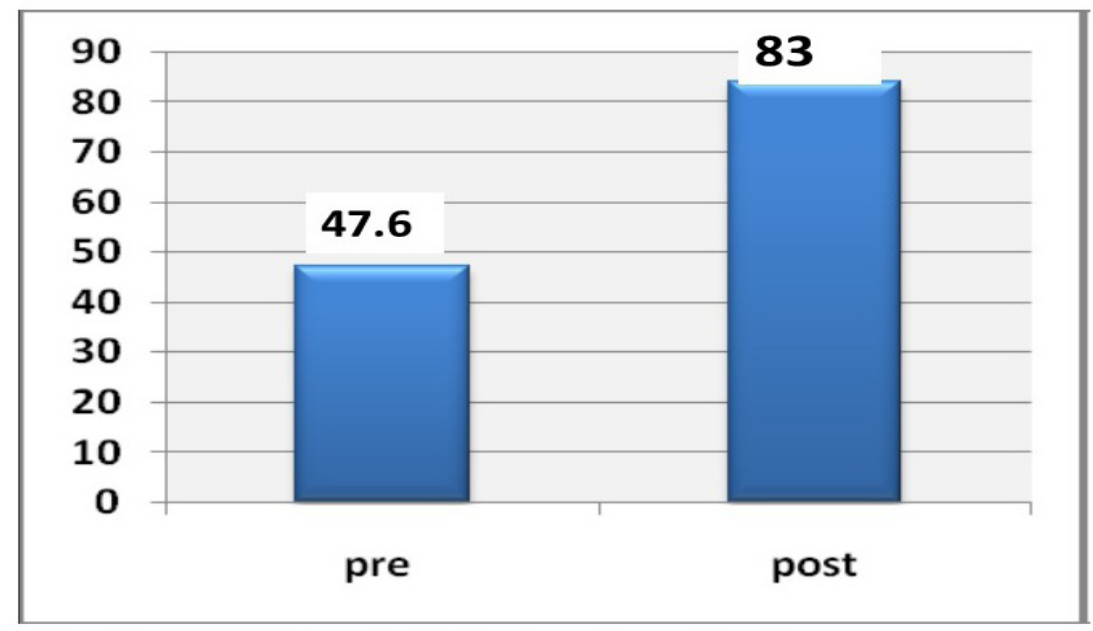

The total CDSS (chondral defect scoring system)

The mean total objective preoperative (CGSS) score was 19.6 (SD \pm 7.6$)$ and postoperative mean 35 (SD \pm 5.8 ) also improved. The mean preoperative for R.O.M. was $4.4(\mathrm{SD} \pm 2.8)$ improved to $9.3(\mathrm{SD} \pm 1.8)$ postoperative. Effusion was improved from $3.4(\mathrm{SD} \pm 2.3$ ) to $7.6(\mathrm{SD} \pm 2.6)$ postoperative. According to chondral defect scoring system (CDSS), the mean total subjective (CDSS) score was improved from 26.5 (SD \pm 9.2 ) preoperatively to a mean of $48.5(\mathrm{SD} \pm 46.6)$ postoperatively. The subjective mean score forpain was significantly improvedfrom 9.5 ( $\mathrm{SD} \pm 2.5$ ) preoperatively, to 15.3 ( $\mathrm{SD} \pm 2$ ) postoperatively.The mean scorefor swelling was improved from 3.2 $(\mathrm{SD} \pm 2.4)$ preoperatively to postoperative mean of $7.6(\mathrm{SD} \pm 2.6)$.The mean preoperative score for locking was $6.2(\mathrm{SD} \pm 4.6)$ was increased to $10(\mathrm{SD} \pm 0.003)$ postoperative. Full weight bearing was achieved at 3 months for all patients and they were able to return to their normal activities. The preoperative mean for pain during work was $8.6(\mathrm{SD} \pm 3.9)$ and improved to $16.4(\mathrm{SD} \pm 3.1)$ postoperatively. 


\section{Treatment of Knee Osteochondral Defects with Mosaicoplasty Technique}

The Lysholm score has shown significant improvement of the Limp from a mean preoperative score of 2.3 (SD \pm 1.1 ) to amean of $4.6(\mathrm{SD} \pm 0.8$ ) postoperative. The use ofsupport (cane or crutches) improved frompreoperative mean of $2(\mathrm{SD} \pm 1.5)$ to postoperative mean $4.8(\mathrm{SD} \pm 0.8)$. The locking sensation in the knee changed from preoperative mean of $6.5(\mathrm{SD} \pm 4.5)$ to postoperative mean of 2.9 ( $\mathrm{SD} \pm 2$ ). The mean preoperative score of swelling was improved from $3(\mathrm{SD} \pm 2.1)$ to a postoperative mean of $8.6(\mathrm{SD} \pm 2.2)$. Giving say sensation score (Knee Instability) changed from preoperative meanof 17.5 ( $\mathrm{SD} \pm 4.8$ ) to postoperative mean 23 (SD \pm 2.6 ). Preoperative mean score for climbing stairs was3.5 ( $\mathrm{SD} \pm 2$ ) changed to postoperative mean of 7.6 ( $\mathrm{SD} \pm 2$ ); also score for squatting was improved from preoperative mean of 2.6 (SD \pm 1.1 ) to postoperative mean of 4.8 (SD \pm 0.6 ).According to Lysholm score 4 patients (25\%) had excellent score, 10 patients (62.5\%), 2 patients (12.5\%) fair, and no patient had poor score (Chart 2).

Chart2.

\section{Lysholm score 1 year postoperative}

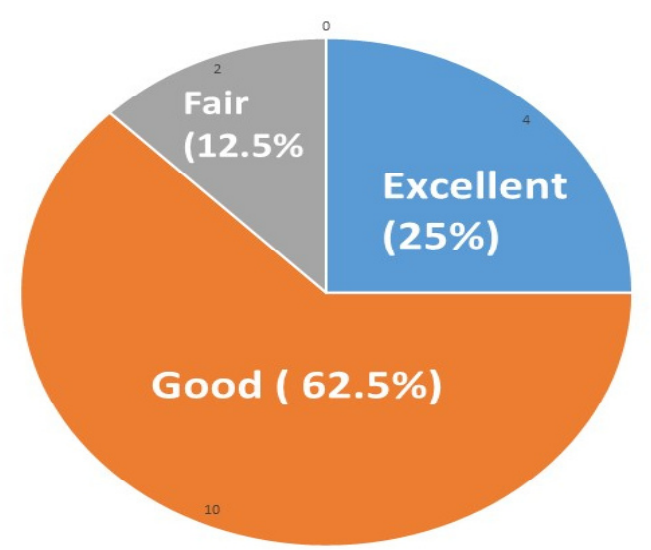

Radiologically all grafts were united and incorporation was achieved in a mean time of 10 months range 512 months (Fig 3).

\section{DISCUSSION}

The treatment of articular cartilage lesions still a challenge due to the poor intrinsic capacity for repair. Pain and dysfunction are the results of untreated lesions. The technique of osteochondral autograft transplantation is well-established for treatment of the chondral and osteochondral defects and also called mosaicoplasty. Mosaicoplasty can be carried by open or arthroscopic technique with no difference on the outcome except for the wound in open procedure.

Ulstein, et al. 2014 [10] has Fifteen patients with mean age of 32.7 (SD \pm 7.8 ), lesion size between 2-4 cm,11 case in medial femoral condyle and 4 patients in lateral femoral condyle. Mini-invasive arthrotomy mosaicoplasty was performed through a medial parapatellar approach, depending on the lesion size and localization. Mean Lysholm score for the patients preoperative 49.2 to postoperative 69.7 at 2 year follow-up.In the study of Solheim, et.al.2010 [11] on thirty-three patients with age of 50 years or younger and thesize of articular cartilage defects ranged from 1 to $5 \mathrm{~cm}$. Clinically they reported an improvement of outcome evaluated by Lysholm score from a mean preoperative score of 48 to a mean postoperative score of 82.3 after one year follow up.

Ma, et.al. 2004 [12] has treated 18 patients with posttraumatic focal knee osteochondral defects with osteochondral autograft transfer. There had 12 males and 6 females with a mean age of 29 years (range: 16 to 51 y). The medial femoral condyle was affected in 12 patients, and lateral femoral condyle in 6 . The Lysholm scores changed from preoperative score of 47.5 (range 35-60), to a post-operative score of 92.4 (range 79-100). 


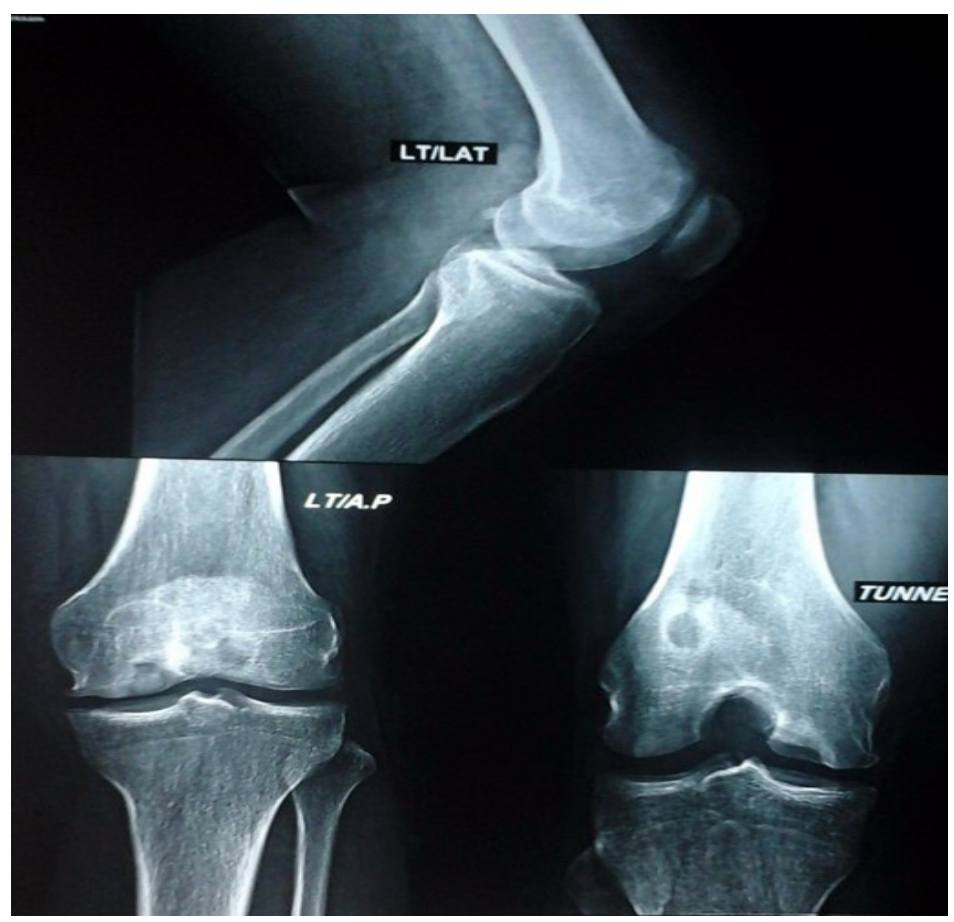

Figure3. direct postoperative $x$-ray, and one year follow up $x$-ray

Thirty-seven active patients younger than 50 years were treated by Marcacci, et al. 2005 [13]. Confirmed by arthroscope, the patients had grade IV lesion of the medial or lateral femoral condyle less than $2.5 \mathrm{~cm}$ were selected for the study. Themosaicoplasty technique results in this series were satisfactory in $78 \%$ of cases at 2-year follow-up.Chow et al, 2004 [14] reported good or excellent results in 83\% of 30 patients with follow up of 2 to 5 years patients. MRI at the final follow-up showed $92 \%$ restoration of the chondral surface.Gudas,et al 2005[15] reported on 27 patients treated by OATs with score system improvement from $77.88 \pm 6.23$ preoperative, to $91.08 \pm 4.15$ postoperative with follow-up 20-30 months.

The postoperative rehabilitation was found important for the success of the technique to regain range of motion and reducing postoperative effusion.

\section{CONCLUSION}

Mosaicoplasty as one-step procedure,has low morbidity, independent of laboratory use. Based upon the results of this study,osteochondral autograft is a good solution for treatment of full thickness cartilage damage. The limitations of this study are the small number of cases and the relatively short follow up period.

\section{REFERENCES}

1. Ulrich-Vinther M; Maloney M; Schwarz E. Articular Cartilage Biology. Journal of American Academy Orthopedic Surgery (2003) ;(11): pp 421-430.

2. Williams R.J; and Brophy R.H. Decision Making in Cartilage Repair procedure. In Cartilage Repair Strategies (2007); Edited by Williams R.J; 1st edition, Human Press Inc, Totowa, NewJersey, pp: 37-54.

3. Mckeon B.P. Current concept in Articulaqqqq r Cartilage: In Knee arthroscopy, edited by Mckeon B.P; Bono J. V. and Richmon J.K, Ist edition, Springer Science (2009) , pp 97-113. 
4. Treme G; and Miller M. Autograft Osteochondral Transfer: In operative technique Sports Medicine, Elsevier; 2008 (16):18-88.

5. Rodrigo J. and Stedman J.R. Improvement of full thickness chondral defect healing in the human knee after debridement and microfracture using continuous passive motion; American Journal of knee surgery (1994); No.7:pp.109-116.

6. Tegner Y, and Lysholm J. Rating systems in the evaluation of knee ligament injuries. Clinical Orthopedic and Related Research 1985; 198:43-49.

7. Robert H. Chondral repair of the knee joint using mosaicoplasty; Orthopedics and traumatology surgery and research; (2011); 97(4), pp: 418-429.

8. Levy A.S. osteochondral autograft for the treatment of focal cartilage lesions. Operative Techniques in Orthopedics 2011, Vol 11, No 2: pp. 108-114.

9. Hangody L.; Vasarhelyi G.; Hangody L.R.; and Sukosd Z. Autologous Osteochondral grafting technique and long-term results. Injury, International J. Care Injured; 2008; 3951, p532-539.

10. Ulstein S; Arøen A. Røtterud J.H. Microfracture technique versus osteochondral autologous transplantation mosaicoplasty in patients with articular chondral lesions of the knee: a prospective randomized trial with longterm follow-up. Knee Surgery Sports Traumatol Arthroscopy 2004; (22); pp1207-1215.

11. Solheim E.; Hegna J.; Øyen J. Osteochondral autografting (mosaicoplasty) in articular cartilage defects in the knee. The Knee 2010; (17) pp. 84-87.

12. Ma H.; Hung S.; Wang S. Osteochondral autografts transfer for post- traumatic osteochondral defect of the knee. Injury, Int. J. Care Injured 2004, 35, pp. 1286- 1292.

13. Marcacci M.; Kon E; Zaffagnini S; Iacono F. Multiple Osteochondral Arthroscopic Grafting (Mosaicoplasty) for Cartilage Defects of the Knee: Prospective Study Results at 2-Year Follow-up. The Journal of Arthroscopic and Related Surgery 2004, Vol 21 (4) pp 462-470.

14. Chow JC, Hantes ME, Houle JB. Arthroscopic autogenous osteochondral transplantation for treating knee cartilage defects: A 2- to5-year follow-up study. Arthroscopy 2004; 20:681-690.

15. Gudas R. Kalesinskas R.J.; Kimtys V. A Prospective Randomized Clinical Study of Mosaic Osteochondral Autologous Transplantation Versus Microfracture for the Treatment of Osteochondral Defects in the Knee Joint in Young Athletes. The Journal of Arthroscopic and Related Surgery 2005, Vol 21, No 9: pp 1066-1075

Citation: Mohsen Fawzy Omar, MD, Mohammed A Gheith, MD. "Treatment of Knee Osteochondral Defects with Mosaicoplasty Technique". American Research Journal of Orthopedics and Traumatology; V2, I1; pp: 1-9

Copyright (C) 2017 Mohsen Fawzy Omar, MD, Mohammed A Gheith, MD. This is an open access article distributed under the Creative Commons Attribution License, which permits unrestricted use, distribution, and reproduction in any medium, provided the original work is properly cited. 